\title{
Children monosensitized to pine nuts have similar patterns of sensitization
}

\author{
Elio Novembre ${ }^{1}$, Francesca Mori ${ }^{1}$, Simona Barni ${ }^{1}$, Giuliana Ferrante ${ }^{2}$, Neri Pucci ${ }^{1}$, Cinzia Ballabio ${ }^{3}$, \\ Francesca Uberti ${ }^{3}$, Elena Penas ${ }^{3} \&$ Patrizia Restani $^{3}$ \\ ${ }^{1}$ Department of Pediatric, Allergy Unit, A. Meyer Children Hospital, Florence, Italy; ${ }^{2}$ Biomedicine and Molecular Immunology Institute, 'A. \\ Monroy' (IBIM), Consiglio Nazionale delle Ricerche (CNR), Palermo, Sicily, Italy; ${ }^{3}$ Department of Pharmacological Sciences, State University \\ of Milan, Milan, Italy
}

To cite this article: Novembre E, Mori F, Barni S, Ferrante G, Pucci N, Ballabio C, Uberti F, Penas E, Restani P. Children monosensitized to pine nuts have similar patterns of sensitization. Pediatr Allergy Immunol 2012: 23: 761-764.

\section{Keywords}

children; immunoblotting; pine nuts allergy

\author{
Correspondence \\ Elio Novembre, Department of Pediatric, \\ Allergy Unit, A. Meyer Children Hospital, \\ University of Florence, Viale Pieraccini, 24, \\ 50139 Florence, Italy. \\ Tel.: +390555662955 \\ Fax: +390555662400 \\ E-mail: e.novembre@meyer.it; \\ f.mori@meyer.it
}

Accepted for publication 6 September 2012

DOI:10.1111/pai.12012

\begin{abstract}
Background: Several cases of pine nut allergies and anaphylaxis have been reported in the literature, but only few pine nut allergens have been characterized. The aim of this research is to identify through immunoelectrophoretic techniques the major pine nut allergens in a group of children monosensitized to pine nuts.

Methods: We studied five children with pine nut allergies and no other sensitization to food except to pine nuts, confirmed by in vivo (prick test, prick-to-prick) and in vitro tests (specific IgE determinations [CAP-FEIA]). The protein profile of pine nuts was analyzed by Sodium Dodecyl sulfate Polyacrylamide Gel Electrophoresis (SDSPAGE). Immunoblotting was performed after incubation of membranes with the sera from the children included in the present study.

Results: Immunoblotting (SDS-PAGE) demonstrated five similar bands between 6 and $47 \mathrm{kDa}$ in all the subjects studied.

Conclusion: These bands should be considered the potential allergens for pine nut allergic children.
\end{abstract}

Food allergy is a common disease in childhood with increasing prevalence $(1,2)$ and relative high risk of anaphylactic reactions, which are difficult to manage from both a therapeutical (3-5) and a psychological point of view $(6,7)$. In particular, nut allergy (8) such as peanut, tree nut, hazel nut, cashew nut, and pistachio nut, may provoke severe allergic reactions (9).

Pine nuts are the seeds of Pinus pinea, which is a typical conifer in southern Europe, especially in Italy, southern France and Spain. Nowadays, there is a renewed interest in pine nuts as a food, and they are consumed raw or toasted, and are included as ingredients in salads, pastries and sauces such as the typical Italian sauce 'Pesto alla Genovese.' Although several cases of pine nut allergies and anaphylaxis have been reported in the literature (10-16), only few pine nut allergens have been characterized (17-21). Moreover, some studies have described cross-reactivity between pine seeds and other nuts $(22,23)$ or pine pollen $(24)$. Taking into account the previous information, the aim of this research is to identify through immunoelectrophoretic techniques the major pine nut allergens in a group of children monosensitized to pine nuts. The serological characterization of these children's sera will provide information about the specificity and sensitivity of the in vitro diagnostic tests and clinical symptoms, and the risk of $\operatorname{IgE}$ cross-reactions with other tree nuts.

\section{Material and methods}

Patients

The sera of five children (three males and two females) with history of immediate $(<1 \mathrm{~h})$ allergic reactions following the ingestion of pine nuts and positive skin prick tests and/or serum specific IgE to pine nuts were collected at the Department of Pediatrics, Meyer Hospital (Florence, Italy); participant age ranged from 5 to 13 yrs (mean [s.d.] age, 11.90 [3.53]). Anaphylaxis was diagnosed according to the clinical criteria proposed by Sampson et al. (25). Informed consent was obtained from the parents of all children participating in this study. This study has been performed according to the Declaration of Helsinki, and it has been approved by A. Meyer's ethics committee.

\section{Skin tests}

Skin prick tests were performed with common allergens (mites, pollens, molds, and epithelia) and food (egg, milk, wheat, corn, 
tree nut, hazelnut, pine nut, pistachio nut, peanut, cod, sole, snail, shrimp, peach, apple, kiwi, carrot, tomato) of commercial origin (ALK Abelló, Madrid, Spain). Saline was used as a negative control and $10 \mathrm{mg} / \mathrm{ml}$ histamine phosphate as a positive control. Results were read after $15 \mathrm{~min}$. Reactions were considered to be positive if the largest diameter of the wheal was $3 \mathrm{~mm}$ over the negative control. Skin tests with fresh nuts (peanut, pine nut, tree nut, almond, cashew nut, pistachio) were also performed by prick-to-prick method according to Ortolani et al. (26) in the patients and in 10 control subjects.

\section{Specific IgE determination}

Specific IgE against a panel of most common food allergens (milk, egg, cod, wheat, peanut) and nuts (tree nut, hazelnut, almond, pine nut, pistachio nut) was determined by CAP (CAP System, Pharmacia, Uppsala, Sweden).

\section{Preparation of pine nut samples}

Pine nuts (Conad, Bologna, Italy) were purchased from a local supermarket and were ground to minute particles using a coffee mill. The protein content of the resultant flour was determined according to the method described by Lowry et al. (27). Pine nut flour was then defatted by adding diethyl ether for $2 \mathrm{~h}$ at $4^{\circ} \mathrm{C}$. After centrifugation (5000 revolution per minute, $20 \mathrm{~min}$ ), the supernatant was discarded and the precipitate was extracted twice more. Afterward, the defatted flour was suspended in a sample buffer (containing $0.125 \mathrm{M}$ TRIS- $\mathrm{HCl} \mathrm{pH} 6.8,3.75 \%$ glycerol, $1 \%$ SDS, 5\% $\beta$-Mercaptoethanol) diluted with water $(1: 1, \mathrm{v}: \mathrm{v})$ at a final concentration of $10 \mathrm{mg} / \mathrm{ml}(\mathrm{w} / \mathrm{v})$. This sample was used to perform the Sodium Dodecyl Sulfate-Polyacrylamide Gel Electrophoresis (SDS-PAGE) and immunoblotting.

\section{Sodium dodecyl sulfate-polyacrylamide gel electrophoresis (SDS-PAGE)}

The protein profile of pine nuts was analyzed by SDS-PAGE. For this purpose, defatted pine nut flour was suspended in a sample buffer (containing 0.125 м TRIS- $\mathrm{HCl}$ pH 6.8, 3.75\% glycerol, $1 \%$ SDS) diluted with water $(1: 1, \mathrm{v}: \mathrm{v})$ at a final concentration of $10 \mathrm{mg} / \mathrm{ml}(\mathrm{w} / \mathrm{v})$ and $10 \mathrm{ml}$ of this sample was loaded in a gel having the following characteristics:

Gradient running gel: $9-19 \%$ acrylamide; $0.08-0.17 \%$ bisacrylamide; 0.36 м TRIS-HCl buffer $\mathrm{pH} 8.8 ; 35 \%$ glycerol; $0.1 \%$ SDS; $0.02 \%$ ammonium persulfate; and $0.15 \% \mathrm{~N}, \mathrm{~N}, \mathrm{~N}$, N'-tetramethylenediamine (TEMED).

Stacking gel: $3.5 \%$ acrylamide; $0.09 \%$ bis-acrylamide; 0.125 м TRIS-HCl buffer pH 6.8; $0.1 \%$ SDS; $0.02 \%$ ammonium persulfate; and $0.15 \%$ (TEMED).

Running buffer: $25 \mathrm{~mm}$ TRIS, $0.19 \mathrm{~m}$ glycine and 0.1\% SDS (w/v), $\mathrm{pH} 8.8$.

After the electrophoretic run $(90 \mathrm{~V}$ at room temperature, for approximately $6 \mathrm{~h}$ ), gels were dyed with Coomassie Brilliant Blue G-250 by the method of Neuhoff et al. (28). All materials and instruments were purchased from Bio-Rad (Richmond CA, USA).
A prestained molecular-weight marker solution (broad range, Bio-Rad) contained myosin $(202.8 \mathrm{kDa}), \beta$-galactosidase $(115.6 \mathrm{kDa})$, bovine serum albumin $(98.2 \mathrm{kDa})$, ovalbu$\min (51.4 \mathrm{kDa})$, carbonic anhydrase $(37.2 \mathrm{kDa})$, soybean trypsin inhibitor (29 kDa), lysozyme (19.7 kDa), and aprotinin $(6.7 \mathrm{kDa})$.

\section{Immunoblotting}

After SDS-PAGE, pine nut proteins were transferred into a Polyvinylidene fluoride (PVDF) membrane (Millipore, Billerica, MA, USA) by Western blotting in a Trans-blot Electrophoretic Transfer Cell (Bio-Rad). The membranes were blocked with $1 \%$ gelatin and washed three times with $0.25 \%$ gelatin solution (150 mм NaCl, $5 \mathrm{~mm}$ TRIS, $0.05 \%$ Triton-X) to prevent non-specific adsorption of the immunological reagents. Afterward, the membrane was immersed in $10 \mathrm{ml}$ of $0.25 \%$ gelatin solution containing $20 \mu \mathrm{l}$ of human sera. Antigen-IgE complex were detected using $10 \mu \mathrm{l}$ of goat antihuman IgA polyclonal antibodies labeled with alkaline phosphatase (Chemicon International, Temecula, CA, USA). Finally, after incubation in the bromochloroindolyl phosphate-nitroblue tetrazolium (BCIP/NBT) solution, an intense black-purple precipitate developed at the site of the enzyme binding. The developing solution contained $15 \%$ bromochloroindolyl phosphate and 30\% nitroblue tetrazolium in alkaline phosphatase buffer (100 mm TRIS, $100 \mathrm{~mm}$ sodium chloride, and 5 mм magnesium chloride, $\mathrm{pH} 9.5$ ).

\section{Results}

Two patients reported symptoms of anaphylaxis and three symptoms of urticaria-angioedema. All five children resulted only sensitized to pine nuts and negative to all the other food tested (in two cases there was also a sensitization to Dermatophagoides pteronyssinus and grass pollen as shown in Table 1). Figure 1 illustrates the results obtained by SDSPAGE of pine nuts and the corresponding immunoblotting after incubation of membranes with the sera from the children included in the present study. The electrophoretic pattern of pine nuts under reducing conditions (lane 1) showed 10 protein

Table 1 Clinical and immunological characteristics of the studied patients

\begin{tabular}{lllll}
\hline $\begin{array}{l}\text { Pt.N/age/ } \\
\text { sex }\end{array}$ & Symptoms & $\begin{array}{l}\text { Pine nut } \\
\text { Serum IgE } \\
\text { (KU/L) }\end{array}$ & $\begin{array}{l}\text { P-to-P } \\
(\mathrm{mm})\end{array}$ & $\begin{array}{l}\text { Other } \\
\text { sensitizations }\end{array}$ \\
\hline 1/13/F & OAS/N/LE-D & 5.3 & 12 & Grass \\
2/13/M & OAS/U & 4.5 & 5 & - \\
3/13/M & OAS & 0.79 & 10 & - \\
4/13/M & OAS/LE/D & 27 & 5 & - \\
5/5/F & OAS/U & 12.1 & 15 & Dust mite \\
\hline
\end{tabular}

Pt., patient; N, number; P-to-P, Prick-to-Prick; F, female; M, male; OAS, oral allergy syndrome; V, vomit; LE, laryngeal edema; D, Dyspnoea; U, urticaria. 


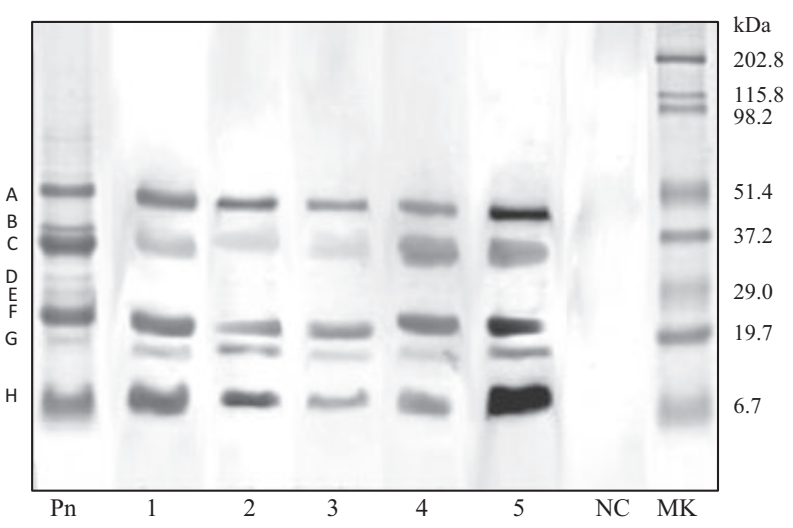

Figure 1 Sodium dodecyl sulfate polyacrylamide gel electrophoresis (SDS-PAGE) of pine seed and immunoblotting obtained after incubation of membranes with five different sera from children monosensitized to pine nut. Lane Pn: Pine nut electrophoretic profile; Lanes 1-5: immunoblotting of pine nut incubated with sera from allergic patients; Lane NC: Negative control; Lane MK: Prestained molecular weight marker; $\mathrm{kDa}$ : molecular weight unit.

Table 2 Estimated molecular weight of the major pine nuts proteins

\begin{tabular}{ll}
\hline Protein band & $\begin{array}{l}\text { Molecular } \\
\text { weight }(\mathrm{kDa})\end{array}$ \\
\hline Band A & 47.1 \\
Band B & 38.3 \\
Band C & 34.8 \\
Band D & 27.7 \\
Band E & 24.2 \\
Band F & 20.7 \\
Band G & 15.4 \\
Band H & 6.6 \\
\hline
\end{tabular}

bands with a molecular weight ranging from $\sim 7$ to $58 \mathrm{kDa}$ (Table 2). Figure 1 also shows the results obtained by immunoblotting after incubating the membranes, which contain the pine nut proteins (showed in lane 1) with the sera from the five children monosensitized to pine nuts included in this study (lanes 2-6). As expected, all subjects reacted strongly to pine nuts and, furthermore, they presented a similar IgE reactivity pattern to pine nut proteins. Specific IgE reactivity against five pine protein bands were observed in all the children: bands $A$ $(\sim 47.1 \mathrm{kDa}), \mathrm{C}(\sim 34.8 \mathrm{kDa}), \mathrm{F}(\sim 20.7 \mathrm{kDa}), \mathrm{G}(\sim 15.4 \mathrm{kDa})$, and $\mathrm{H}(\sim 6.6 \mathrm{kDa})$.

\section{Discussion}

Systemic symptoms ranging from urticaria to anaphylactic reactions have been described in patients with pine nut allergy $(10-16,23)$. Acute anaphylactic reactions after pine nut skin tests have also been reported (29) in the literature. In our study, two children presented anaphylaxis and three urticaria-angioedema after ingestion of pine nuts. All children were sensitized to pine nuts and not to other food tested (in two cases, there was also a sensitization to mixed grass and D. pteronissuns, Table 1). Recently, a case report about a young boy with several episodes of anaphylaxis after pine nut ingestion was described (30). Specific $\operatorname{IgE}$ to pine nuts and Artemisia vulgaris were demonstrated by skin prick tests and in vitro CAP, although specific IgE to pine pollen or other nuts were no detected. Immunoblotting of $A$. vulgaris and pine nuts revealed two matching diffuse bands, just below 14 and $30 \mathrm{kDa}$. The ImmunoCAP inhibition assays showed a complete inhibition of pine nut specific IgE after serum incubation with the $A$. vulgaris extract, indicating cross-reactivity between pine nut and $A$. vulgaris. In our study, however, none of the children were sensitized to $A$. vulgaris even if bands at $\sim 15$ and $34 \mathrm{kDa}$ were found. Nevertheless, other further sensitization to inhalants as well as to food allergens in the group of children studied cannot be excluded. Several authors have studied and characterized different allergens in pine nuts through immunoblotting techniques. In this regard, Koepke et al. (14) showed the presence of 30 protein bands by electrophoresis of a pine nut extract in an immunoblot. Three of such protein bands (ranging between 66 and $68 \mathrm{kDa}$ ) bound the serum $\operatorname{IgE}$ of a patient with pine nut anaphylaxis. Recently, a 7-vicilintype globulin from the Korean pine was purified and characterized (20).

Allergens from pine nut may induce severe allergic reactions. Ibañez et al. (15) described two cases of young girls with anaphylaxis caused by ingestion of small amounts of pine nuts. The patients had IgE against a specific pine nut protein band with an apparent molecular weight of approximately $17 \mathrm{kDa}$ that could be considered as the main pine nut allergen. As the patients were monosensitized to pine nuts, it was suggested that the $17-\mathrm{kDa}$ protein could be correlated with the most severe clinical symptoms. In this study, five protein bands were recognized by the sera from the children monosensitized to pine nuts. Some of these immunoreactive bands, with a molecular weight $\sim 15.4$ and $47.1 \mathrm{kDa}$, could correspond to those described in other studies $(15,18,22,30)$. It should be emphasized that the monosensitized children included in this work can be considered a homogeneous and well-characterized group of patients allergic to pine nuts in which all the true allergenic bands could be identified. All five allergic children had specific IgE to the same proteic bands: A (47.1 kDa), C (34.8 kDa), F (20.7 kDa), G (15.4 kDa), H (6.6 kDa). No differences were detected in the IgE response in subjects with anaphylaxis compared with those without anaphylaxis, and for this reason, all the immunoreactive bands may have clinical relevance without apparent correlation with the severity of the symptoms. Further studies will be necessary to investigate the relative clinical importance of the single bands.

\section{Acknowledgment}

We thank all of the participating subjects and families.

\section{Conflict of interest}

The authors declare that they have no conflict of interest. 


\section{Sources of funding}

This study was supported by University of Florence and A. Meyer Children Hospital, Florence, Italy.

\section{References}

1. McBride D, Keil T, Grabenhenrich L, et al. The EuroPrevall birth cohort study on food allergy: baseline characteristics of 12,000 newborns and their families from nine European countries. Pediatr Allergy Immunol 2012: 23: 230-9.

2. Prescott S, Allen KJ. Food allergy: riding the second wave of the allergy epidemic. Pediatr Allergy Immunol 2011: 22: 155-60.

3. Flokstra-de Blok BM, Doriene van Ginkel C, Roerdink EM, et al. Extremely low prevalence of epinephrine-auto injectors in high risk food allergic adolescents in Dutch high school. Pediatr Allergy Immunol 2011: 22: 374-7.

4. Arroabarren E, Lasa EM, Olaciregui I, Sarasqueta C, Muñoz JA, Pérez-Yarza EG. Improving anaphylaxis management in a Pediatric Emergency Department. Pediatr Allergy Immunol 2011: 22: 708-14.

5. Johnson MJ, Foote KD, Moyses HE, Roberts G. Practices in the prescription of adrenaline autoinjectors. Pediatr Allergy Immunol 2012: 23: 125-8.

6. Zijlstra WT, Flinterman AE, Soeters L, et al. Parental anxiety before and after food challenges in children with suspected peanut and hazelnut allergy. Pediatr Allergy Immunol 2010: 21: e439-45.

7. Gupta RS, Springston EE, Smith B, et al. Food allergy knowledge, attitudes, and beliefs of parents with food-allergic children in the United States. Pediatr Allergy Immunol 2010: 21: 927-34.

8. Cummings AJ, Knibb RC, ErlewynLajeunesse M, King RM, Roberts G, Lucas JS. Management of nut allergy influences quality of life and anxiety in children and their mothers. Pediatr Allergy Immunol 2010: 21: 586-94.

9. Crespo JF, James JM, Fernandez-Rodriguez C, Rodriguez J. Food allergy: nuts and tree nuts. Br J Nutr 2008: 99: 447-8.

10. Falliers CJ. Pinu nut allergy in perspective. Ann Allergy 1989: 62: 186-9.
11. Rubira N, Botey J, Eseverri JL, Marin A. Allergy to pine nuts in children. Allerg Immunol 1998: 30: 212-6.

12. Jansen A, Vermeulen A, Dieges PH, van Toorenenbergen AW. Allergy to pine nuts in a bird fancier. Allergy 1996: 51: 741-4.

13. Anò MA, Maselli JP, Sanz Mf ML, Fernández-Benítez M. Allergy to pine nut. Allergol Immunopathol 2002: 30: 104-8.

14. Koepke JW, Williams PB, Osa SR, Dolen WK, Selner JC. Anaphylaxis to piñon nuts. Ann Allergy 1990: 65: 473-6.

15. Ibáñez DM, Lombardero M, Martinez San Ireneo M, Muñoz MC. Anaphylaxis induced by pine nuts in two young girls. Pediatr Allergy Immunol 2003: 14: 317-9.

16. Rossi G. A case of severe allergy to pinenut. Eur Ann Allergy Clin Immunol 2007: 39: 344-5.

17. Garcia-Menaya JM, Gonzalo-Garijo MA, Moneo I, Fernández B, García-González F, Moreno F. A $17-\mathrm{kDa}$ allergen detected in pine nuts. Allergy 2000: 55: 291-3.

18. Cabanillas B, Grimm CC, Crespo JF, et al. Initial characterization of two pine nut seed allergens. J Allergy Clin Immunol 2011: 127: Issue2: AB112: p. 1A-4A. Suppl.

19. Jin T, Albillos SM, Chen YW, Kothary MH, Fu TJ, Zhang YZ. Purification and characterization of the 7S vicilin from Korean pine (Pinus Koraiensis). J Agric Food Chem 2008: 56: 8159-65.

20. Jin T, Fu TJ, Kothary MH, Howard A, Zhang YZ. Crystallization and initial crystallographic characterization of a vicillin-type seed storage protein from Pinus koraiensis. Acta Crystallogr Sect F Struct Biol Cryst Commun 2007: 63: 1041-3.

21. Sathe SK, Venkatachalam M, Sharma GM, Kshirsagar HH, Teuber SS, Roux KH. Solubilization and electrophoretic characterization of select edile nut seed proteins. J Agric Food Chem 2009: 57: 784656.
22. De las Marinas D, Vila L, Sanz ML. Allergy to pine nuts. Allergy 1998: 53: 220-2.

23. Roux N, Hogendijk S, Hauser C. Severe anaphylaxis to pine nuts. Allergy 1998: 53: 213-4.

24. Senna G, Roncarolo D, Dama A, Mistrello G. Anaphylaxis to pine nuts and immunological cross-reactivity with pine pollen proteins. J Investig Allergol Clin Immunol 2000: 10: 44-6.

25. Sampson H, Munoz-Furlong A, Campbell $\mathrm{RL}$, et al. Second symposium on the definition and management of anaphylaxis: summary report - Second National Institute of Allergy and Infectious Diseases/Food Allergy and Anaphylaxis Network Symposium. J Allergy Clin Immunol 2006: 117: 391-7.

26. Ortolani C, Ispano M, Pastorello EA, Ansaloni R, Magri GC. Comparison of results of skin prick tests (with fresh foods and commercial food extracts) and RAST in 100 patients with oral allergic syndrome. $J$ Allergy Clin Immunol 1989: 83: 683-90.

27. Lowry OH, Rosebrough NJ, Farr AL, Randall RJ. Protein measurement with the Folin-Phenol reagents. J Biol Chem 1951: 193: 265-75.

28. Neuhoff V, Arold N, Taube D, Ehrhardt W. Improved staining of proteins in polyacrylamide gels including isoelectric focusing gels with clear background at nanogram sensitivity using Coomassie Brilliant Blue G-250 and R-250. Electrophoresis 1988: 9: 550-2.

29. van de Scheur MR, Bruynzeel DP. Acute anaphylaxis after pine nut skin testing. Ann Allergy Asthma Immunol 2004: 92: 93.

30. Rodrigues-Alves R, Pregala A, Pereira-Santosb MC, et al. Anaphylaxis to pine nut: cross-reactivity to Artemisia vulgaris? Allergol Immunopathol 2008: 36: 113-6. 